\title{
Modelling and Solving Assembly Line Worker Assignment and Balancing Problem with Sequence- Dependent Setup Times
}

Hamid YILMAZ ( $\nabla$ hamidyilmaz@gmail.com )

Bayburt University https://orcid.org/0000-0003-0852-4119

\section{Research Article}

Keywords: Mixed integer linear programming, Assembly line balancing, Simulated annealing, Sequencedependent setup times

Posted Date: May 24th, 2021

DOl: https://doi.org/10.21203/rs.3.rs-539741/v1

License: (c) (i) This work is licensed under a Creative Commons Attribution 4.0 International License.

Read Full License

Version of Record: A version of this preprint was published at Soft Computing on August 12th, 2021. See the published version at https://doi.org/10.1007/s00500-021-06107-3. 


\title{
Article Title Page
}

\section{MODELLING AND SOLVING ASSEMBLY LINE WORKER ASSIGNMENT AND BALANCING PROBLEM WITH SEQUENCE-DEPENDENT SETUP TIMES}

\section{Author Details:}

[Author 1 Name] Hamid YILMAZ

[Author 1 Affiliation] Bayburt University, Faculty of Engineering, Industrial Engineering Department, Bayburt/TURKEY

Corresponding author: Hamid YILMAZ

Corresponding Author's Email: hamidyilmaz@bayburt.edu.tr

\begin{abstract}
:
Assembly lines appear with various differentiations in order to better include the disabled in the labor market and to increase production efficiency. In this way, the optimal workforce assignment problem that emerges heterogeneously is called assembly line worker assignment and balancing problem (ALWABP). This paper addresses the ALWABP where the simple version is enriched by considering sequence-dependent setup times between tasks. A mixed integer linear programming model is presented and a simulated annealing algorithm is developed such as an NP-hard problem. In order to test the proposed solutions, 640 benchmark problems in the literature were combined and used. The solutions obtained through using the proposed algorithm are compared with the mixed integer programming model on the small-size test problems. Experimental results show that the proposed algorithm is more effective and robust for a large set of benchmark problems.
\end{abstract}

Keywords: Mixed integer linear programming, Assembly line balancing, Simulated annealing, Sequence-dependent setup times

Article Classification: Research Article 


\title{
MODELLING AND SOLVING ASSEMBLY LINE WORKER ASSIGNMENT AND BALANCING PROBLEM WITH SEQUENCE-DEPENDENT SETUP TIMES
}

\author{
Hamid YILMAZ ${ }^{1}$ \\ ${ }^{1}$ Bayburt University, Faculty of Engineering, Industrial Engineering Department, \\ Bayburt/TURKEY
}

\begin{abstract}
Assembly lines appear with various differentiations in order to better include the disabled in the labor market and to increase production efficiency. In this way, the optimal workforce assignment problem that emerges heterogeneously is called assembly line worker assignment and balancing problem (ALWABP). This paper addresses the ALWABP, where the simple version is enriched by considering sequence-dependent setup times between tasks. A mixed-integer linear programming model is presented, and a simulated annealing algorithm is developed such an NP-hard problem. In order to test the proposed solutions, 640 benchmark problems in the literature were combined and used together. The solutions obtained through using the proposed algorithm are compared with the mixedinteger programming model on the small-size test problems in terms of solution quality and running time. Experimental results show that the proposed algorithm is more effective and robust for a large set of benchmark problems.
\end{abstract}

Keywords: - Mixed integer linear programming, Assembly line balancing, Simulated annealing, Sequence-dependent setup times

\section{1-Introduction}

Assembly lines have been used extensively to produce high-volume products in the industry and one of the well-known research areas in the production environment [1]. Assembly line balancing problem can be defined as assigning tasks to workstations, considering the constraints on the line. In addition, it has to be optimized with specific objectives, such as cycle time minimization for a predetermined number of the workstations or workstation minimization for a predetermined cycle time (Ct). Also, Assembly processes include between $15 \%$ and $70 \%$ of manufacturing lead time and $40 \%$ of manufacturing costs [2, 3]. A considerable amount of research on solving conventional ALB problems is available in the literature $[4,5]$. In addition, conventional ALBP is known as the NP-hard problems $[6,7]$. The detailed reviews of such studies are given by Scholl and Becker [8] and Becker and Scholl [9].

Another variant of ALBP considers worker assignments. This is a major problem found in sheltered work centers for disabled. Some employees may need more time to perform certain tasks or may not be able to do so. Because of the growing interest and respect for the disabled, many industries employing them, and companies are always concerned with assigning workers on assembly lines [10]. In this case, one of the most critical issues is that there are workers with different skill levels. There are various models created for this purpose, and such lines are called assembly line worker assignment and balancing problems (ALWABP) in the literature. In cases where task times depend on the worker, it is important to decide on assigning tasks [11]. For this reason, a high-skill level worker can perform the task quickly while, the worker with a lower skill level could more time to complete the task. ALWABP tries to determine the most appropriate assignment for both workers and workstations as 
seen in Figure 1 [12]. ALWABP is an assembly line balancing problem involving worker assignment and task allocation sub-problems. Worker assignment aims to distribute tasks evenly across workstations by satisfying different constraints such as precedence and cycle time constraint, while determining the assignment of workers to workstations [13].

Figure 1. Assignment example of workers and tasks for ALWABP

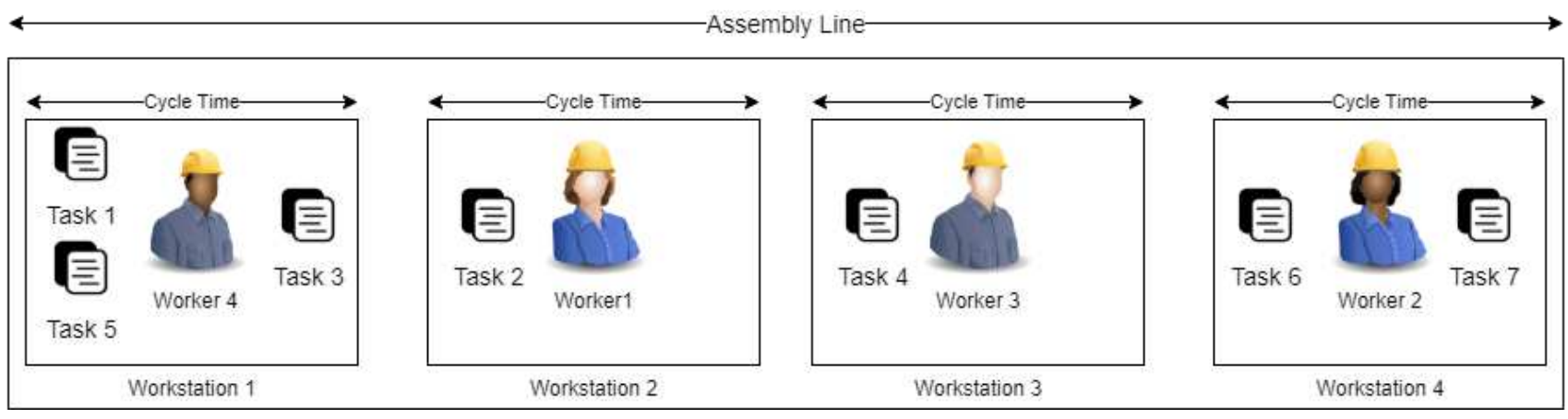

In the real world planning environment, more are occurring than the constraints involved in assembly lines. For this reason, it has become a necessity to offer solutions considering these additional constraints.

For most industrial assembly lines, setups are assumed to be negligible because their time is very short compared to task time. As a result of this situation, it is not necessary to specify task execution sequences in a workstation, but task execution order is an important issue in order to minimize station time in case of sequence-dependent setup times. Therefore, in the real world planning environment it may be necessary to consider sequence- dependent setup times in ALWBP. Performing one task directly before another task can affect the completion time of the next task within the same station, since a setup may be required to perform the second task. Also, if a task is assigned to a worker in a station as the last one, it may need setup-time to perform the first task assigned to that station [14]. Andres et al. first introduced balancing and scheduling tasks in assembly lines with sequencedependent setup times [15].

Most of the published papers about sequence dependent setup times have focused extensively on various line balancing problems except ALWABP [13-30]. ALWABP has been criticized for lacking reallife application since the problem structure in a real-world planning environment is much more complex. To the authors' best knowledge, no study has been reported on ALWABP with the objective of minimizing cycle time under sequence-dependent setup times. To fill this gap in the literature, the following major contributions are presented in this research. The first contribution is to present the ALWABP problem with sequence-dependent setup times for the first time. Also, a new mixed integer programming model is formulated and solved by GUROBI to solve small-sized problems. The second contribution is that, a metaheuristic algorithm developed to solve the large-sized problems. However, the result quality and CPU times of the proposed heuristic method were also compared with the mathematical model.

This paper is organized as follows. After the introduction, the ALWABP literature review is presented in Section 2. In Section 3, problem description and the MIP formulation of the problem is presented. In Section 4 the proposed simulated annealing algorithm for solving ALWABP is given in detail. The computational results with the application of MIP formulation and the results of the meta-heuristic algorithm on a set of test problems are presented and discussed in Section 5-6. Finally, some conclusions and implications for further research are presented in the last section. 


\section{Literature review}

In this section, firstly, the literature on assembly lines with setup time is given. Then assembly line worker assignment and balancing problems are presented. Dolgui et al. reported that the study of assembly line balancing, scheduling and design problems are widely studied in the literature [13]. However, there are various studies on assembly line problems with sequence dependent setup times in the literature. Andres et al. first introduced balancing and scheduling tasks in assembly lines with sequence-dependent setup times. A binary integer programming model and greedy randomized adaptive search procedure is presented [15]. Scholl et al. defined a new problem and formulated a mixed-integer program for the sequence-dependent assembly line balancing problem. Also, they generated test data for computational experiments [16]. Martino and Pastor [17] presented a heuristic to solve the same problem as Andres et al. [15]. Özcan and Toklu presented a mixed integer program and a COMSOAL based heuristic algorithm to solve two-sided assembly line balancing problems with sequence-dependent setup times [14]. A mathematical formulation using mixed integer programming for sequence dependent task times in multi-model production has been developed by Nazarian et al. [18]. Seyed-Alagheband et al. has developed a mathematical model and a simulated annealing (SA) algorithm to solve type II assembly line balancing problems with sequence-dependent setup times [19]. Yazdanparast et al. discussed the general assembly line balancing problem with setups and formulated a mathematical model to solve the problem [20]. Yolmeh and Kianfar considered setup assembly line balancing and scheduling problem and proposed a hybrid genetic algorithm to solve the problem [21]. Scholl et al. extended the problem by introducing backward setups. Also, they have proposed a mathematical program, and heuristics algorithms in order to solve the problem [22]. Kalayci and Gupta considered sequence-dependent disassembly line balancing problem. However, a particle swarm optimization algorithm has been proposed to solve the problem [23]. Akpınar et al. have presented a new hybrid ant colony algorithm with genetic algorithm for mixed-model assembly line balancing problem type I with real world constraints such as zoning constraints, parallel workstations, and sequence dependent setup times between tasks [24]. Hamta et al. have presented multi-objective optimization of single model assembly line balancing problem with sequencedependent setup time exists between tasks and have proposed a particle swarm optimization algorithm with variable neighborhood search to solve it [25]. Akpınar and Baykasoğlu have presented a mixed-model assembly line balancing problem with sequence-dependent setup times. Besides a mixed integer linear programming formulation and hybrid bee algorithm has been proposed to solve the problem $[26,27]$. Şahin and Kellegöz have developed a mixed-binary integer programming model, a simulated annealing algorithm and a genetic algorithm for the U-type assembly lines with sequencedependent setup times [28]. Akpınar et al. have proposed an exact solution algorithm based on Benders decomposition for setup assembly line balancing problem [29]. Özcan have introduced parallel assembly line balancing problem with sequence-dependent setup times. Also, they have proposed mathematical programming model and a simulated annealing algorithm to solve the problem [30]. Yang and Cheng have examined the multi-manned assembly line balancing problem, which is widely used in large-sized productions, with sequence dependent setup times. A mixedinteger programming is presented and a simulated annealing algorithm is also proposed to solve it. [45].

Regarding worker assignment and balancing problems, Miralles et al. have introduced sheltered work centers in assembly line balancing and formulated a mathematical model [11]. Chaves et al. have proposed a hybrid heuristic based on clustering search to solve ALWABP [31]. Miralles et al. have defined a mathematical model for ALWABP and a branch and bound approach with different search strategies to solve the problem [32]. Chaves et al. have proposed a hybrid method based on clustering search to solve the ALWABP [33]. Blum and Miralles have developed a beam search method to solve 
assembly worker assignment and balancing problems [10]. Moreira et al. have introduced a constructive heuristic based on priority rules of task-worker [34]. Mutlu et al. have developed a genetic algorithm to solve the problem. Also, results of the algorithm show that the proposed method is very robust and effective for large test instances [35]. Vila and Pereira derived new lower bounds for the ALWABP. Nevertheless, they have developed an exact algorithm to solve the problem. This proposed branch and bound algorithm yields state-of-the-art results for ALWABP [36]. Ramezanian and Ezzatpanah presented a mixed-model assembly line balancing and worker assignment problem. A goal programming solution procedure has been proposed to solve the problem [37]. Akyol and Baykasoğlu proposed a constructive heuristic approach for the ALWABP. Performance of the algorithm is compared with the relevant literature on test instances. Experimental results show that the proposed approach is very effective on test instances [38]. Janardhanan et al. studied worker assignment and line balancing problem in two-sided assembly lines. They have developed a mixed-integer programming model, and a migrating birds algorithm to solve the problem [39].

In order to adapt the solutions offered to assembly lines to real world systems, the problem should be examined together with the constraints such as sequence-dependent setup times encountered in the real world. When the literature is examined, it is seen that the ALWABP has not been studied together with the sequence-dependent setup time constraints. The presented study is the first study in the literature in terms of analyzing the assembly line worker assignment and balancing problem with sequence-dependent setup times (ALWABPS). Also, in this study, two main elements of setup times are considered between tasks: forward and backward setups, and the objective is to minimize the cycle time for workstations. Another contribution to the literature of the paper is to formulate a new mixed integer programming model. Furthermore, a computational study using a simulated annealing (SA) algorithm as a metaheuristic approach for test instances, involving up to 2 setup group (low and high) and total 640 test instances, is presented.

\section{Assembly line worker assignment and balancing problem with sequence-dependent setup times (ALWABPS)}

\subsection{Problem definition}

ALWABP, which minimizes the cycle time, can be formally expressed as: A set "I" of tasks, a set "W" of workers, and a set "WS" of stations are given by a line designer to perform these tasks. Some workers are unable to perform a number of tasks because they do not have some skills or they have a disability. Let " $W \subseteq W$ " be the subset of workers that can perform task " $i \in I$ ". However, let " $\mathrm{I}_{\mathrm{W}} \subseteq \mathrm{I}$ " be the subset of tasks that can be performed by worker " $w \in W$ ". For each task " $i$ " that can be performed by worker " $w$ ", " $\mathrm{Z}_{\mathrm{iw}}$ " expresses the time required by the worker " $w$ " to perform the task " $\mathrm{i}$ " and it is called the task time. Some tasks have precedence relationships where the current task cannot be performed before the previous one. The objective of the problem is to ensure that all work pieces (tasks) assigned to the workstation can be performed by the workers at that station, precedence relations between tasks are fulfilled and the cycle time of workstations is minimized [40].

Between tasks, there are two types of sequence-dependent setup times. These are forward setup and backward setup, respectively. At the same workstation, If task " $\mathrm{i}$ " is performed just before another task " $\mathrm{h}$ ", a forward setup occurs for the same workpiece to perform task " $\mathrm{h}$ ". It is called forward setup time, and " $\mu_{\mathrm{ih}}$ " is added to the workstation time. In a regular workstation, if task " $\mathrm{i}$ " is the last assigned task in a workstation and task " $\mathrm{h}$ " is the first assigned task at the same workstation, then it is called backward setup. It is necessary to to perform task $h$, a backward setup time, $\mathrm{t}_{\mathrm{ih}}$, is added to compute workstation cycle time. 
A detailed illustration of assembly line worker assignment and balancing with sequence-dependent setup times is given in Figure 1. As seen in Figure 2, Worker 3 is assigned to Workstation 1 and " 1 - 5 3 " tasks are assigned to him. At the same time, these assignments are " $2-4$ " tasks for the Worker 1 , and " 6 - 7" for the Worker 2 . Setup times, i.e., forward setups; $\mu_{15}$ and $\mu_{24}$, and backward setups; $t_{31}$ and $t_{42}$, are also shown in Figure 2.

Figure 2. Illustration of ALWABP with sequence-dependent setup times.

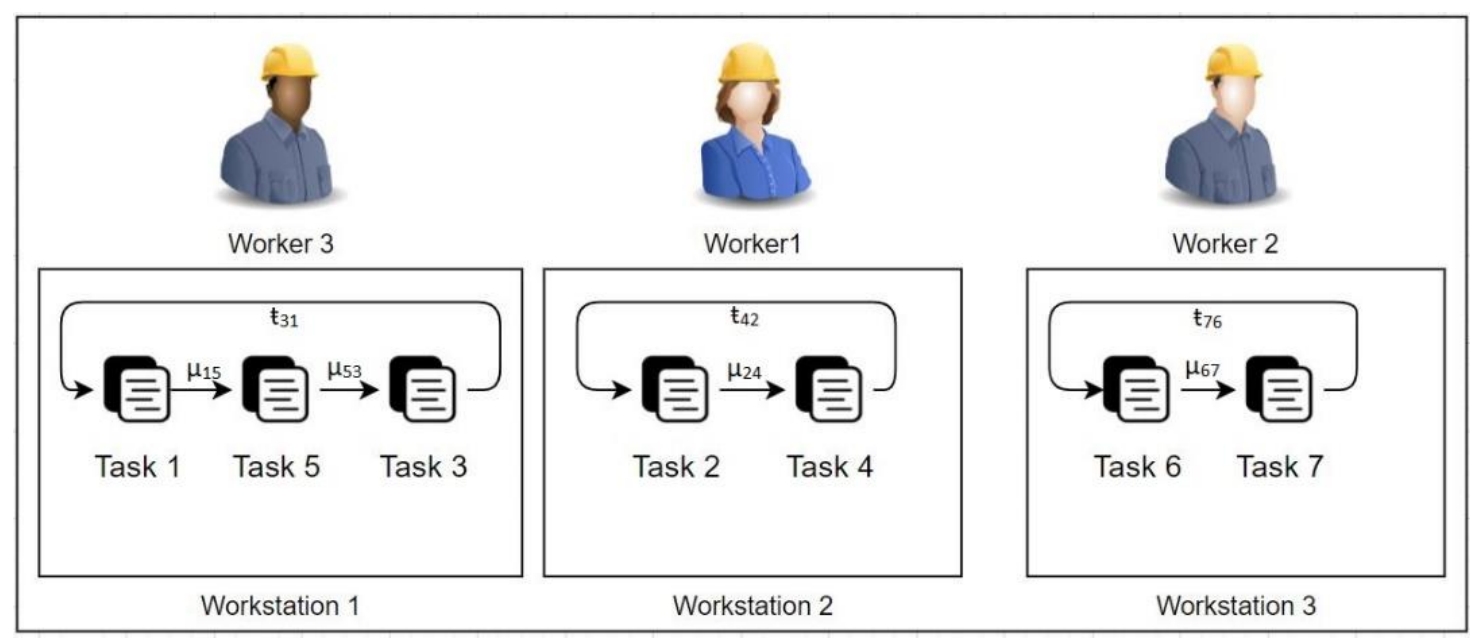

In this paper, it is assumed that the problem considered under the following conditions:

- The task times are deterministic and known in advance.

- Not all workers may be able to perform all tasks.

- A task can be assigned to only one workstation.

- A task can be assigned to only one worker.

- A single model product is produced.

- The precedence relationships are known in advance.

- All components are available with no quality problems.

- The forward and backward setup times deterministic and known in advance.

- Each task must be performed.

- No breakdowns occur in the assembly line.

\subsection{Notations}

The notations used in MILP of the problem are given as follows.

Indices:

$\mathrm{i}, \mathrm{h}: \mathrm{A}$ task.

$\mathrm{j}$ : A workstation.

w: A worker.

s: A position inside the task operation sequence of a workstation.

\section{Parameters and Sets:}

c: Cycle time.

$t_{i w}$ : Task time of "i" at worker " $w$ ". 
SN: Maximum number of tasks that can be assigned to any station.

P: Set of immediate predecessors of tasks.

WS: Number of workstations.

WW: Number of workers.

SN: Number of positions.

T: Number of tasks.

I: Set of tasks. $I=\{1,2, \ldots ., \mathrm{i}, \ldots . T\}$

$W=$ Number of assignable workers on the line. $W=\{1,2, \ldots ., W, \ldots W W\}$

$J=$ Number of workstations on the line. $J=\{1,2, \ldots, j, \ldots W S\}$

$S=$ Number of positions in a station. $S=\{1,2, \ldots ., S, \ldots S N\}$

M: A big number.

Decision variables:

$\mathrm{x}_{\mathrm{ijws}}: 1$, if task " $\mathrm{i}$ " in workstation " $\mathrm{j}$ " is assigned to worker " $\mathrm{w}$ " in position " $\mathrm{s}$ " of its operation sequence; 0 , otherwise.

$Y_{j w}: 1$, if worker " $w$ " is assigned to workstation " $w$ "; 0 , otherwise.

$p f_{\text {ihjw: }} 1$, if task " $i$ " is the immediate processor of task " $h$ " in workstation "j" at worker " $w$ "; 0 , otherwise.

$p b_{\text {ihjw: }} 1$, if task "i" is the last task and " $h$ " is the first task assigned to workstation " $j$ " at worker " $w$ "; 0 , otherwise.

$!_{\mathrm{ijw}}: 1$, if task is the last task assigned to workstation " $\mathrm{j}$ " at worker " $w$ "; 0 , otherwise.

\subsection{Mixed integer programming model of ALWABPS}

In this study, presented mathematical model is as follows;

$$
\begin{gathered}
\text { Minimize c (1) } \\
\sum_{j \in J} \sum_{w \in W} \sum_{s \in S} x_{i j w s}=1, \forall(i) \in I \quad \text { (2) } \\
\sum_{i \in I} x_{i j w s} \leq 1, \forall(j) \in J, \forall(w) \in W, \forall(s) \in S \text { (3) } \\
\sum_{j \in J} y_{j w}=1, \forall(w) \in W(4) \\
\sum_{w \in W} y_{j w}=1, \forall(j) \in J(5) \\
\sum_{i \in I} \sum_{s \in S} x_{i j w s} \leq M * y_{j w}, \forall(j) \in J, \forall(w) \in W(6)
\end{gathered}
$$




$$
\begin{gathered}
\sum_{i \in I} x_{i j w(s+1)}-\sum_{i \in I} x_{i j w s} \leq 0, \forall(j) \in J, \forall(w) \in W, \forall(s) \in\{1,2, \ldots \ldots \ldots(S N-1)\}(7) \\
\sum_{j \in J} \sum_{w \in W} \sum_{s \in S}(S N *(j-1)+s) * x_{i j w s}-\sum_{j \in J} \sum_{w \in W} \sum_{s \in S}(S N *(j-1)+s) * x_{h j w s} \leq 0, \forall(j) \in J, \forall(w) \\
\in W, \forall(s) \in S,(i, h) \in P(8) \\
\sum_{i \in I} \sum_{s \in S} \sum_{w \in W} t_{i w} * x_{i j w s}+\sum_{(i, h) \in I, i \neq k} \sum_{s \in S} \sum_{w \in W} t s f_{i h} * p f_{i h j w}+\sum_{(i, h) \in I} \sum_{s \in S} \sum_{w \in W} t s b_{i h} * p b_{i h j w} \\
\leq c * \sum_{w \in W} y_{j w}, \forall(j) \in J(9) \\
x_{i j w s}+x_{h j w(s+1)}-p f_{i h j w} \leq 1, \forall(j) \in J, \forall(i, h) \in I, i \neq h, \forall(s) \in\{1,2, \ldots \ldots \ldots(S N-1)\}(10) \\
x_{i j w s}-\sum_{h \in I} \sum_{w \in W} x_{h j w(s+1)} \leq l_{i j w}, \forall(j) \in J, \forall(i, h) \in I, i \neq h, \forall(s) \in\{1,2, \ldots \ldots \ldots(S N-1)\}(11) \\
l_{i j w}+x_{h j w 1}-p b_{i h j w} \leq 1, \forall(j) \in J, \forall(i, h) \in I, \forall(s) \in S(12) \\
\sum_{w \in W} y_{(j+1) w}-\sum_{w \in W} y_{j w} \leq 0, \forall(j) \in\{1,2, \ldots .(J-1)\}(13) \\
x_{i j w s} \in\{0,1\}, \forall(i) \in I, \forall(j) \in J, \forall(w) \in W, \forall(s) \in S(14) \\
y_{j w} \in\{0,1\}, \forall(j) \in J, \forall(w) \in W(15) \\
p f_{i h j w} \in\{0,1\}, \forall(i, h) \in I, \forall(j) \in J, \forall(w) \in W(16) \\
p b_{i h j w} \in\{0,1\}, \forall(i, h) \in I, \forall(j) \in J, \forall(w) \in W(17) \\
l_{i j w} \in\{0,1\}, \forall(i) \in I, \forall(j) \in J, \forall(w) \in W(18)
\end{gathered}
$$

The objective of the model is to minimize the cycle time of workstations of the assembly line (1). Constraints 2, ensures that each task is assigned to a worker in a workstation to a position. Constraint 3 , ensures that not more than one task is assigned to a position in a workstation. Constraints 4 and 5 , ensures that each worker is assigned to a single workstation and a workstation can only have one worker. Constraint 6 , checks whether a station has been opened. The constraint 7 allows the task positions (time period) to be opened sequentially. Constraint 8 ensures that all precedence relations among tasks of all assembly lines are satisfied, regarding not only the assignment to different workstations, but also the time period inside the same workstations. Constraints 9 ensure that the workstation global time in every workstation, including forward setup times, backward setup times and processing times of tasks, is under the cycle time. If " $\mathrm{i}$ " and " $\mathrm{h}$ " tasks are assigned to " $\mathrm{s}$ " and " $\mathrm{s}+1$ " positions respectively in workstation " $\mathrm{j}$ " at worker " $\mathrm{w}$ ", it is ensured that $p f_{\text {injw }}$ takes the value of 1 by constraint 10 . If the task " $\mathrm{i}$ " is the last task at worker " $\mathrm{w}$ " in workstation " $\mathrm{j}$ ", $l_{i j w}$ takes the value " 1 " by constraint 11 . If task " $i$ " is the last job in workstation " $\mathrm{j}$ " at worker " $w$ " and job " $\mathrm{h}$ " is the first job in the same station, then $p b_{\text {ihjw }}$ gets the value " 1 " by constraint 12 . The constraint 13 , allows the stations to be opened sequentially. Constraints $14-19$ are variables.

\section{Proposed algorithm}


Simulated annealing is an iterative random search algorithm and it has been used in many optimization problems including ALBP [41, 42]. Originally, simulated annealing was introduced as an optimization method by Kirkpatrick et al. [43]. In this paper, a simulated annealing algorithm is proposed to ALWABPS that is able to solve problem sizes of real-world environment.

The proposed simulated annealing algorithm is described by the following procedure: SA is initialized with predetermined parameter settings such as initial temperature " $\mathrm{T}_{\mathrm{i}}$ ", cooling rate " $\mathrm{Cr}$ ", the number of iterations for each temperature level (TL), and the stop criteria as finish temperature " $\mathrm{T}_{f}$ ". SA starts with an initial solution " $\mathrm{S}_{\text {" }}$ " with the cost, " $\mathrm{CO}_{i}$ ". " $\mathrm{S}_{i}$ " can be obtained with a constructive heuristic using specific or random priority rules for the problem. " $\mathrm{CO}_{i}$ " is the objective function value for the solution of " $\mathrm{S}_{i}$ ". In the case, " $\mathrm{S}_{\mathrm{i}}$ " value is assigned to the current solution "CS" and the best solution "BS". The cost of "CS" and "BS" is calculated as " $\mathrm{CO}_{c}$ " and " $\mathrm{CO}_{b}$ ", respectively. SA iterations begin with obtaining the initial solution by a constructive heuristic. Using a move operator, a neighbor solution "NS" is generated. The neighbor solution cost " $\mathrm{CO}_{\mathrm{Ns}}$ " is calculated and compared to " $\mathrm{CO}_{\mathrm{C}}$ ". Afterwards the changes in the objective function values are calculated by " $\Delta \mathrm{CO}=\mathrm{CO}_{\mathrm{NS}}-\mathrm{CO}_{\mathrm{c}}$ ". If " $\mathrm{CO}_{\mathrm{NS}}$ " is better than " $\mathrm{CO}_{c}$ ", then "NS" is assigned to "CS". If " $\mathrm{CO}_{\mathrm{NS}}$ " is worse than " $\mathrm{CO}_{\mathrm{c}}$ ", there are two different conditions called as the Metropolis criterion. The first condition is accepting "NS" as "CS" with the probability of $\mathrm{e}^{-\Delta C O / t e m p}$ ( $\mathrm{T}_{\mathrm{c}}$ " is the current temperature and initially " $\mathrm{T}_{c}$ " is equal to " $\mathrm{T}_{i}$ "). The second condition is that "CS" remains unchanged, if the first condition is not met. Thus, accepting worse solutions by the algorithm increases the capability of jumping out of local optima. If " $\mathrm{CO}_{c}$ " is better than " $\mathrm{CO}_{b}$ ", then "CS" is accepted as "BS"; otherwise "BS" remains unchanged. The algorithm repeats this process " $\mathrm{TL}$ " times at each temperature level. The parameter " $\mathrm{T}_{c}$ " is slowly decreased as in " $\mathrm{T}_{\mathrm{c}}=\mathrm{T}_{\mathrm{c}}$. Cr" by a cooling function until the stopping condition " $T_{c}<T_{f}$ " is met. The algorithm will run, until the stopping criteria is satisfied.

Initial solution: In this paper, a worker-oriented strategy to get a feasible solution is presented. The workers are assigned to the workstations. Then, tasks are assigned to workers sequentially, taking the priority value of workers and tasks into consideration. In order to explain the initial solution generation is as follows:

1- Generate a random number between $0-1$ by uniform distribution for each worker and task for assembly line.

2- Select the workers from highest priority to lowest and assign them to the workstations.

3- Determine the set of assignable tasks for the current workstation $\mathrm{j}=1$.

4- Sort the tasks in decreasing (priority rule) order.

5- Select the assignable first task " $\mathrm{i}$ ", then assign the task to workstation " $\mathrm{j}$ ". Otherwise close the workstation " $\mathrm{j}$ " and select the next workstation as $\mathrm{j}=\mathrm{j}+1$. If workstation is the last station, go to step 6; otherwise go to Step 4.

6- If all tasks are assigned to workers, then stop and save the solution as the initial solution. Otherwise, change worker priorities in turn and go to Step 2.

Neighbor generation: New line balance is created by reassign tasks to workers in workstations by using a move operator. In this algorithm, a swap operator is used. The operator ensures that the priority values of the two selected tasks are changed as seen in Figure 3 . This operator has been applied to both tasks and workers. A new neighbor solution is created from the current solution by using the swap operator in each step of the algorithm. 
Figure 3. Swap operator for the worker and tasks.
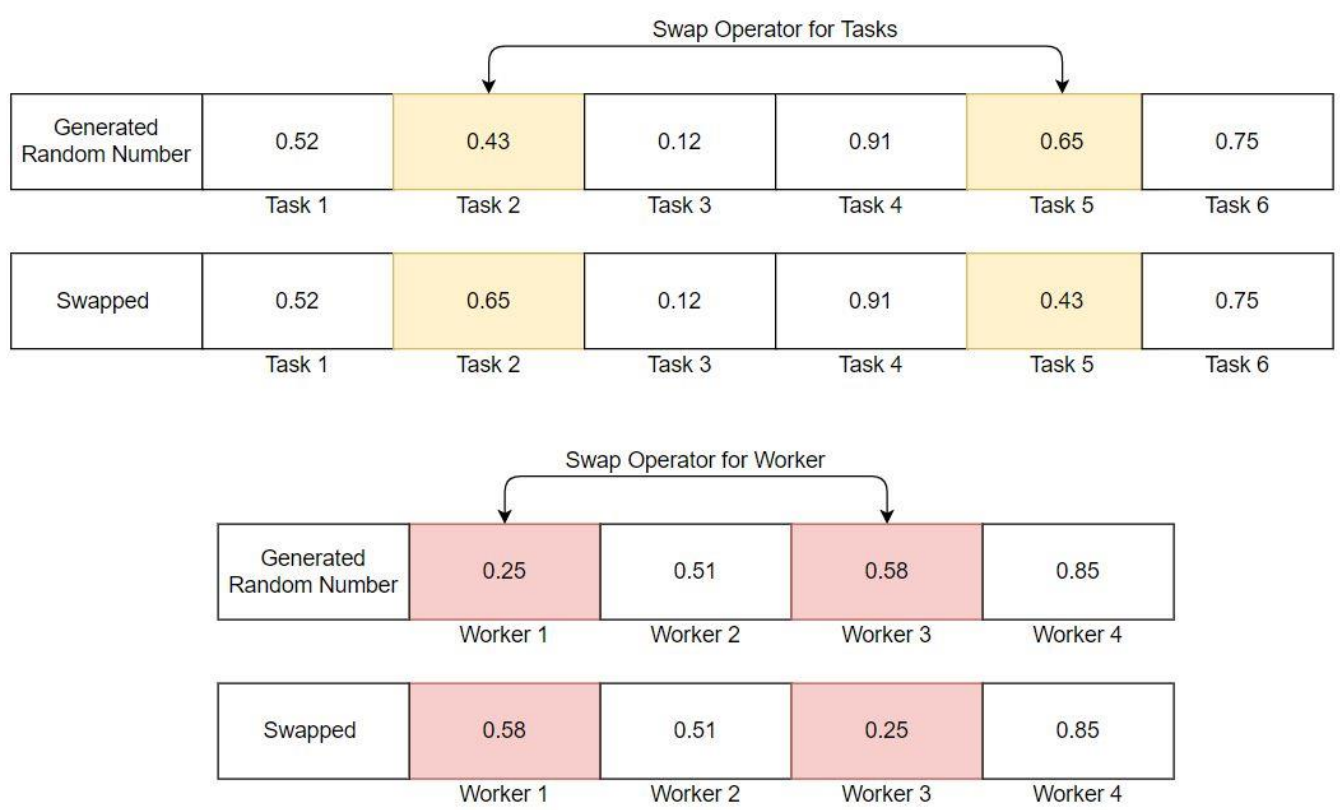

Objective function: Maximum cycle time duration created in workstations on assembly line worker assignment and balancing problem is used as the objective function to evaluate the quality of solutions generated. The objective of the proposed algorithm for the ALWABPS is minimizing the cycle time for a given number of workers.

Stopping criteria: The proposed algorithm terminates when the $T_{f}$ or maximum iteration number (Iter $\left.r_{\max }\right)$ is obtained.

\section{4- Numerical experiment}

The main objective of this study is to introduce and characterize the assembly worker assignment and balancing problem with sequence-dependent setups. With this design, a new mathematical model is presented for the problem. As a solution approach, a metaheuristic approach is proposed. Proposed algorithm is a computationally simple approach and within a short computational time, it can find good solutions. In this paper, the problem of assembly line worker assignment and balancing problem with sequence-dependent setup times is presented for the first time. There is no study on the problem for comparison with the presented algorithm in the literature. Hence, the results of the proposed simulated annealing algorithm are compared with the presented mathematical model solution on small size test instances and solutions of large test instances are enclosed in this paper.

The proposed mathematical model is solved by GUROBI 8.1.1, algorithm is coded by C\# and executed on a PC with Intel(R) Core(TM) i7, $2.20 \mathrm{GHz}$ processor and $8.00 \mathrm{~GB}$ of RAM. Benchmark data is considered from the ALWABP benchmark data set [31]. Test samples are derived through using five 
experimental factors with low and high levels. These factors are; the number of workers, the number of tasks, the variability of the task execution time, the order strength and the number of tasks that cannot be performed by workers. The details of test instance characteristics are given in Table 1 . There are 320 test instances which are named into Heskia, Roszieg, Tonge and Wee-Mag.

Table 1. Characteristics of test instances.

\begin{tabular}{|c|c|l|l|}
\hline Family & $\begin{array}{c}\text { Number of } \\
\text { Tasks }\end{array}$ & \multicolumn{1}{|c|}{$\begin{array}{c}\text { Number of } \\
\text { Workers }\end{array}$} & Order Strength \\
\hline Roszieg & 25 (low) & Group 1- 4 (4 Workers) / Group 5- 8 (6 Workers) & 71.67 (high) \\
\hline Heskia & 28 (low) & Group 1- 4 (4 Workers) / Group 5- 8 (7 Workers) & 22.49 (low) \\
\hline Tonge & 70 (high) & Group 1-4 (10 Workers) / Group 5- 8 (17 Workers) & 59.42 (high) \\
\hline Wee-Mag & 75 (high) & Group 1- 4 (11 Workers) / Group 5- 8 (19 Workers) & 22.67 (low) \\
\hline
\end{tabular}

Each one of the test instance families contains 80 problems. There are 32 task groups and each of them contains 10 test instances. Each task group is defined by the family name and a number between 1 and 8. However, the results of 80 test problems are given in detail for each family. In addition, the test instances presented by Scholl in the literature were used in terms of sequence dependent setup times. Scholl grouped the sequence-dependent setup times of tasks in-to 4 groups $(0.25,0.50,0.75$, and 1.00$)$ as seen in Table 2 [22]. Setup times used in this paper are 0.25 (low) and 1.00 (high) and available for download at "http://www.assembly-line-balancing.de->Datasets". Thus, a total of 640 test instances are presented for ALWABPS.

Table 2. Characteristics of test instances for setup times.

\begin{tabular}{|c|c|c|c|c|}
\hline Family & Test Instance Code & $\begin{array}{c}\text { Setup Time } \\
\text { Level (Low) }\end{array}$ & Test Instance Code & $\begin{array}{c}\text { Setup Time Level } \\
\text { (High) }\end{array}$ \\
\hline Roszieg & heskia_c=138.alb & 0.25 & heskia_c=138.alb & 1.00 \\
\hline Heskia & roszieg_c=16.alb & 0.25 & roszieg_c=16.alb & 1.00 \\
\hline Tonge & Tonge70_c=160.alb & 0.25 & Tonge70_c=168.alb & 1.00 \\
\hline Wee-Mag & wee-mag_c=38.alb & 0.25 & wee-mag_c=38.alb & 1.00 \\
\hline
\end{tabular}

Each test instance was run with the proposed mathematical model for 900 seconds [44] and the results were reported. Thus, the model was run a total of 9000 seconds for just one data set. Since the proposed algorithm is a heuristic method, each instance was run 3 times and best results are reported.

First, Roszieg and Heskia test problem instances were solved and their results were compared with heuristic algorithm. For Roszieg test instances, although 32 problems were solved optimally, other test problems in the same problem family were solved with small gap values. In all test problems, the proposed algorithm has yielded the same results created by the mathematical model as seen in Table 3. In addition, when the mathematical model and heuristic algorithm results are compared in the Heskia family, it is seen that the heuristic algorithm produces better results in a shorter time than the mathematical model as seen in Table 4. Thus, the efficiency of the proposed heuristic algorithm has been demonstrated and tested on large-scale test problems. Large-scale test problems belonging to Tonge and Wee-Mag families were solved with a mathematical model and algorithm, but the mathematical model could not find any solution despite the removal of the time limitation. The heuristic algorithm results are presented in Table 5.

Table 3. Detailed results obtained by mathematical model and heuristic approach for Roszieg family. 


\begin{tabular}{|c|c|c|c|c|c|c|c|c|c|c|c|}
\hline & \multirow{3}{*}{$\begin{array}{c}\text { Family } \\
\text { ROSZIEG } \\
\text { Inst. }\end{array}$} & \multicolumn{6}{|c|}{ Mathematical Model } & \multicolumn{4}{|c|}{ Heuristic Solutions } \\
\hline & & \multicolumn{3}{|c|}{ Setup Level $1(0,25)$} & \multicolumn{3}{|c|}{ Setup Level $4(1,00)$} & \multicolumn{2}{|c|}{$\begin{array}{c}\text { Setup Level } 1 \\
(0,25)\end{array}$} & \multicolumn{2}{|c|}{$\begin{array}{c}\text { Setup Level } 4 \\
(1,00)\end{array}$} \\
\hline & & $\mathrm{C}$ & GAP (\%) & $\mathrm{CPU}(\mathrm{s})$ & $\mathrm{C}$ & GAP(\%) & $\mathrm{CPU}(\mathrm{s})$ & $\mathrm{C}$ & $\mathrm{CPU}(\mathrm{s})$ & $\mathrm{C}$ & $\mathrm{CPU}(\mathrm{s})$ \\
\hline \multirow{11}{*}{ 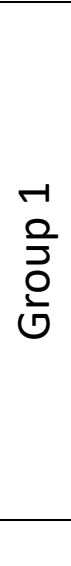 } & 1 & 21 & 0,00 & 244,79 & 26 & 3,84 & 900,00 & 21 & 9,21 & 26 & 9,97 \\
\hline & 2 & 23 & 0,00 & 297,41 & 26 & 0,00 & 520,88 & 23 & 8,79 & 26 & 7,82 \\
\hline & 3 & 19 & 0,00 & 233,89 & 24 & 12,50 & 900,00 & 19 & 8,08 & 24 & 8,59 \\
\hline & 4 & 19 & 0,00 & 405,01 & 22 & 0,00 & 117,34 & 19 & 12,38 & 22 & 10,95 \\
\hline & 5 & 18 & 0,00 & 251,78 & 21 & 0,00 & 497,52 & 18 & 7,04 & 21 & 7,49 \\
\hline & 6 & 25 & 0,00 & 743,88 & 28 & 0,00 & 351,00 & 25 & 7,40 & 28 & 8,51 \\
\hline & 7 & 22 & 0,00 & 175,55 & 25 & 0,00 & 226,85 & 22 & 7,47 & 25 & 10,17 \\
\hline & 8 & 21 & 4,76 & 900,00 & 25 & 0,00 & 336,83 & 21 & 7,09 & 25 & 9,20 \\
\hline & 9 & 23 & 0,00 & 383,35 & 26 & 0,00 & 152,28 & 23 & 10,25 & 26 & 7,69 \\
\hline & 10 & 20 & 0,00 & 164,43 & 25 & 0,00 & 754,25 & 20 & 7,06 & 25 & 11,56 \\
\hline & Avg. & 21,10 & 0,48 & 380,01 & 24,80 & 1,63 & 475,70 & 21,10 & 8,48 & 24,80 & 9,19 \\
\hline \multirow{10}{*}{$\begin{array}{l}\text { N } \\
\text { 을 } \\
\frac{0}{0}\end{array}$} & 11 & 31 & 0,00 & 450,72 & 36 & 0,00 & 349,47 & 31 & 9,52 & 36 & 8,71 \\
\hline & 12 & 28 & 0,00 & 309,86 & 34 & 0,00 & 431,21 & 28 & 7,15 & 34 & 8,00 \\
\hline & 13 & 77 & 2,59 & 900,00 & 84 & 0,00 & 78,43 & 77 & 9,03 & 84 & 7,63 \\
\hline & 14 & 26 & 0,00 & 127,64 & 29 & 0,00 & 654,58 & 26 & 15,37 & 29 & 8,92 \\
\hline & 15 & 27 & 0,00 & 108,76 & 33 & 0,00 & 266,32 & 27 & 11,89 & 33 & 9,96 \\
\hline & 16 & 23 & 0,00 & 397,19 & 28 & 0,00 & 545,72 & 23 & 7,09 & 28 & 10,97 \\
\hline & 17 & 23 & 0,00 & 298,99 & 27 & 0,00 & 451,34 & 23 & 8,24 & 27 & 8,12 \\
\hline & 18 & 21 & 0,00 & 203,72 & 25 & 12,00 & 900,00 & 21 & 7,05 & 25 & 13,47 \\
\hline & 19 & 28 & 0,00 & 149,72 & 31 & 0,00 & 572,72 & 28 & 7,53 & 31 & 11,06 \\
\hline & 20 & 41 & 0,00 & 460,91 & 45 & 0,00 & 170,21 & 41 & 11,03 & 45 & 7,43 \\
\hline & Avg. & 32,50 & 0,26 & 340,75 & 37,20 & 1,20 & 442,00 & 32,50 & 9,39 & 37,20 & 9,43 \\
\hline \multirow{11}{*}{$\begin{array}{l}m \\
\text { 윽 } \\
\text { 인 }\end{array}$} & 21 & 29 & 0,00 & 329,37 & 35 & 14,28 & 900,00 & 29 & 12,44 & 35 & 7,41 \\
\hline & 22 & 31 & 0,00 & 190,27 & 35 & 0,00 & 551,67 & 31 & 10,95 & 35 & 8,94 \\
\hline & 23 & 27 & 0,00 & 745,54 & 31 & 0,00 & 900,00 & 27 & 7,13 & 31 & 12,30 \\
\hline & 24 & 34 & 0,00 & 317,81 & 38 & 0,00 & 390,21 & 34 & 8,86 & 38 & 13,05 \\
\hline & 25 & 29 & 0,00 & 405,01 & 34 & 14,71 & 514,25 & 29 & 10,09 & 34 & 10,19 \\
\hline & 26 & 28 & 0,00 & 244,79 & 32 & 0,00 & 410,62 & 28 & 7,46 & 32 & 8,39 \\
\hline & 27 & 22 & 0,00 & 625,91 & 27 & 0,00 & 545,81 & 22 & 12,98 & 27 & 8,64 \\
\hline & 28 & 29 & 0,00 & 236,29 & 33 & 0,00 & 44,45 & 29 & 9,43 & 33 & 12,76 \\
\hline & 29 & 28 & 0,00 & 218,95 & 31 & 0,00 & 169,86 & 28 & 7,60 & 31 & 7,61 \\
\hline & 30 & 34 & 0,00 & 354,61 & 36 & 2,77 & 900,00 & 34 & 7,94 & 36 & 7,01 \\
\hline & Avg. & 29,10 & 0,00 & 366,86 & 33,20 & 3,18 & 532,69 & 29,10 & 9,49 & 33,20 & 9,63 \\
\hline \multirow{9}{*}{ 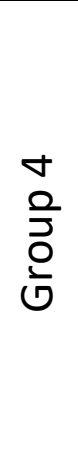 } & 31 & 32 & 0,00 & 257,43 & 36 & 0,00 & 417,25 & 32 & 7,78 & 36 & 8,12 \\
\hline & 32 & 30 & 0,00 & 294,33 & 34 & 2,94 & 900,00 & 30 & 7,49 & 34 & 7,08 \\
\hline & 33 & 33 & 0,00 & 442,87 & 37 & 5,41 & 900,00 & 33 & 11,08 & 37 & 9,15 \\
\hline & 34 & 28 & 3,57 & 900,00 & 33 & 3,03 & 900,00 & 28 & 7,29 & 33 & 7,29 \\
\hline & 35 & 28 & 0,00 & 134,65 & 32 & 0,00 & 133,72 & 28 & 7,54 & 32 & 7,30 \\
\hline & 36 & 30 & 0,00 & 218,55 & 33 & 0,00 & 218,07 & 30 & 9,74 & 33 & 11,13 \\
\hline & 37 & 28 & 0,00 & 451,83 & 31 & 0,00 & 452,85 & 28 & 7,34 & 31 & 7,52 \\
\hline & 38 & 29 & 0,00 & 354,31 & 33 & 0,00 & 353,92 & 29 & 10,35 & 33 & 14,54 \\
\hline & 39 & 22 & 0,00 & 192,07 & 25 & 0,00 & 192,44 & 22 & 8,31 & 25 & 8,29 \\
\hline
\end{tabular}




\begin{tabular}{|c|c|c|c|c|c|c|c|c|c|c|c|}
\hline & 40 & 30 & 0,00 & 749,95 & 33 & 0,00 & 746,71 & 30 & 8,06 & 33 & 7,54 \\
\hline & Avg. & 29,00 & 0,36 & 399,60 & 32,70 & 1,14 & 521,50 & 29,00 & 8,50 & 32,70 & 8,80 \\
\hline \multirow{11}{*}{$\begin{array}{l}\text { L } \\
\frac{\varrho}{7} \\
\text { 인 }\end{array}$} & 41 & 11 & 9,09 & 900,00 & 14 & 28,57 & 900,00 & 11 & 9,52 & 14 & 11,37 \\
\hline & 42 & 11 & 18,18 & 900,00 & 18 & 44,44 & 900,00 & 11 & 12,76 & 18 & 14,70 \\
\hline & 43 & 11 & 0,00 & 505,26 & 16 & 56,25 & 900,00 & 11 & 10,12 & 16 & 10,74 \\
\hline & 44 & 10 & 10,00 & 900,00 & 17 & 50,25 & 900,00 & 10 & 12,67 & 17 & 15,54 \\
\hline & 45 & 13 & 7,69 & 900,00 & 17 & 64,70 & 900,00 & 13 & 9,54 & 17 & 11,22 \\
\hline & 46 & 10 & 10,00 & 900,00 & 17 & 58,88 & 900,00 & 10 & 12,50 & 17 & 9,34 \\
\hline & 47 & 11 & 9,09 & 900,00 & 14 & 66,66 & 900,00 & 11 & 14,72 & 14 & 9,06 \\
\hline & 48 & 9 & 0,00 & 451,83 & 14 & 75,00 & 900,00 & 9 & 10,93 & 14 & 12,01 \\
\hline & 49 & 11 & 0,00 & 749,95 & 15 & 46,13 & 900,00 & 11 & 9,07 & 15 & 11,52 \\
\hline & 50 & 10 & 10,00 & 900,00 & 14 & 42,85 & 609,46 & 10 & 12,38 & 14 & 12,36 \\
\hline & Avg. & 10,70 & 7,41 & 800,70 & 15,60 & 53,37 & 870,95 & 10,70 & 11,42 & 15,60 & 11,79 \\
\hline \multirow{11}{*}{$\begin{array}{l}0 \\
\frac{\Omega}{7} \\
\stackrel{0}{0} \\
0\end{array}$} & 51 & 12 & 8,33 & 900,00 & 26 & 84,61 & 900,00 & 12 & 14,41 & 18 & 10,87 \\
\hline & 52 & 11 & 18,18 & 900,00 & 15 & 66,66 & 900,00 & 11 & 9,84 & 15 & 12,24 \\
\hline & 53 & 11 & 9,09 & 900,00 & 17 & 70,51 & 900,00 & 11 & 12,72 & 15 & 10,80 \\
\hline & 54 & 11 & 9,09 & 900,00 & 17 & 60,00 & 900,00 & 11 & 16,95 & 17 & 17,41 \\
\hline & 55 & 12 & 8,33 & 900,00 & 19 & 57,89 & 900,00 & 12 & 15,60 & 16 & 10,93 \\
\hline & 56 & 14 & 7,14 & 900,00 & 23 & 56,21 & 900,00 & 14 & 14,00 & 20 & 16,57 \\
\hline & 57 & 14 & 7,14 & 900,00 & 27 & 74,07 & 900,00 & 14 & 12,54 & 19 & 12,38 \\
\hline & 58 & 12 & 8,33 & 900,00 & 20 & 75,00 & 900,00 & 12 & 13,45 & 19 & 14,60 \\
\hline & 59 & 13 & 7,69 & 900,00 & 22 & 72,22 & 900,00 & 13 & 10,59 & 16 & 14,45 \\
\hline & 60 & 10 & 10,00 & 900,00 & 19 & 73,84 & 900,00 & 10 & 12,18 & 14 & 13,36 \\
\hline & Avg. & 12,00 & 9,33 & 900,00 & 20,50 & 69,10 & 900,00 & 12,00 & 13,23 & 16,90 & 13,36 \\
\hline \multirow{11}{*}{$\begin{array}{l}\hat{0} \\
\stackrel{2}{7} \\
\stackrel{0}{0}\end{array}$} & 61 & 17 & 5,88 & 900,00 & 25 & 68,00 & 900,00 & 17 & 10,23 & 23 & 10,42 \\
\hline & 62 & 14 & 14,29 & 900,00 & 26 & 73,68 & 900,00 & 14 & 9,88 & 19 & 11,28 \\
\hline & 63 & 20 & 5,00 & 900,00 & 28 & 53,57 & 900,00 & 20 & 10,89 & 26 & 11,38 \\
\hline & 64 & 17 & 5,88 & 900,00 & 27 & 59,25 & 900,00 & 17 & 16,31 & 23 & 10,42 \\
\hline & 65 & 15 & 6,67 & 900,00 & 23 & 56,21 & 900,00 & 15 & 15,89 & 22 & 12,14 \\
\hline & 66 & 18 & 5,56 & 900,00 & 26 & 50,00 & 900,00 & 18 & 9,23 & 26 & 9,99 \\
\hline & 67 & 18 & 5,56 & 900,00 & 24 & 66,66 & 900,00 & 18 & 9,24 & 24 & 17,22 \\
\hline & 68 & 17 & 5,88 & 900,00 & 23 & 62,21 & 900,00 & 17 & 14,54 & 21 & 13,99 \\
\hline & 69 & 16 & 6,25 & 900,00 & 28 & 71,42 & 900,00 & 16 & 11,22 & 19 & 9,39 \\
\hline & 70 & 18 & 5,56 & 900,00 & 24 & 62,50 & 900,00 & 18 & 17,36 & 23 & 9,37 \\
\hline & Avg. & 17,00 & 6,65 & 900,00 & 25,40 & 62,35 & 900,00 & 17,00 & 12,48 & 22,60 & 11,56 \\
\hline \multirow{11}{*}{$\begin{array}{l}\infty \\
\text { 을 } \\
\text { 음 }\end{array}$} & 71 & 16 & 6,25 & 900,00 & 22 & 72,72 & 900,00 & 16 & 10,24 & 22 & 9,75 \\
\hline & 72 & 17 & 11,76 & 900,00 & 24 & 70,83 & 900,00 & 17 & 16,80 & 23 & 9,42 \\
\hline & 73 & 17 & 5,88 & 900,00 & 23 & 39,13 & 900,00 & 17 & 10,51 & 23 & 11,19 \\
\hline & 74 & 17 & 5,88 & 900,00 & 27 & 66,66 & 900,00 & 17 & 15,56 & 21 & 13,37 \\
\hline & 75 & 17 & 5,88 & 900,00 & 21 & 52,38 & 900,00 & 17 & 9,16 & 21 & 11,08 \\
\hline & 76 & 18 & 5,56 & 900,00 & 22 & 63,63 & 900,00 & 18 & 13,63 & 22 & 12,19 \\
\hline & 77 & 14 & 7,14 & 900,00 & 22 & 72,72 & 900,00 & 14 & 12,42 & 19 & 12,00 \\
\hline & 78 & 15 & 6,67 & 900,00 & 20 & 65,00 & 900,00 & 15 & 16,35 & 20 & 16,37 \\
\hline & 79 & 15 & 6,67 & 900,00 & 19 & 47,36 & 900,00 & 15 & 9,04 & 19 & 9,29 \\
\hline & 80 & 15 & 6,67 & 900,00 & 23 & 65,21 & 900,00 & 15 & 9,24 & 23 & 9,89 \\
\hline & Avg. & 16,10 & 6,84 & 900,00 & 22,30 & 61,56 & 900,00 & 16,10 & 12,30 & 21,30 & 11,46 \\
\hline
\end{tabular}


Table 4. Detailed results obtained by mathematical model and heuristic approach for Heskia family.

\begin{tabular}{|c|c|c|c|c|c|c|c|c|}
\hline & \multirow{3}{*}{$\begin{array}{c}\text { Family } \\
\text { HESKIA } \\
\text { Inst. }\end{array}$} & \multicolumn{3}{|c|}{ Mathematical Model } & \multicolumn{4}{|c|}{ Heuristic Solutions } \\
\hline & & \multirow{2}{*}{$\begin{array}{c}\text { Setup Level } 1 \\
(0,25) \\
\mathrm{C}\end{array}$} & \multirow{2}{*}{$\begin{array}{c}\text { Setup Level } 4 \\
(1,00)\end{array}$} & \multirow[t]{2}{*}{$\mathrm{CPU}$} & \multicolumn{2}{|c|}{$\begin{array}{c}\text { Setup Level } 1 \\
(0,25)\end{array}$} & \multicolumn{2}{|c|}{$\begin{array}{c}\text { Setup Level } 4 \\
(1,00)\end{array}$} \\
\hline & & & & & $\mathrm{C}$ & $\mathrm{CPU}$ & $\mathrm{C}$ & CPU \\
\hline \multirow{11}{*}{$\begin{array}{l}\text { ㄱ. } \\
\text { 을 } \\
\text { 인 }\end{array}$} & 1 & 111 & 205 & 900 & 108 & 10,01 & 144 & 13,08 \\
\hline & 2 & 122 & 180 & 900 & 121 & 11,12 & 152 & 18,48 \\
\hline & 3 & 142 & 205 & 900 & 121 & 10,30 & 155 & 10,18 \\
\hline & 4 & 129 & 173 & 900 & 116 & 14,02 & 154 & 11,86 \\
\hline & 5 & 165 & 172 & 900 & 106 & 14,40 & 172 & 11,33 \\
\hline & 6 & 119 & 143 & 900 & 111 & 16,80 & 141 & 10,31 \\
\hline & 7 & 134 & 187 & 900 & 128 & 10,81 & 173 & 14,97 \\
\hline & 8 & 134 & 168 & 900 & 134 & 12,53 & 168 & 11,07 \\
\hline & 9 & 127 & 163 & 900 & 117 & 10,87 & 163 & 12,84 \\
\hline & 10 & 166 & 204 & 900 & 155 & 13,01 & 183 & 15,21 \\
\hline & Avg. & 134,9 & 180 & 900 & 121,7 & 12,39 & 160,5 & 12,93 \\
\hline \multirow{11}{*}{$\begin{array}{l}\text { N } \\
\frac{0}{7} \\
\text { 윤 }\end{array}$} & 11 & 199 & 231 & 900 & 189 & 12,23 & 224 & 12,44 \\
\hline & 12 & 146 & 175 & 900 & 123 & 12,25 & 156 & 17,20 \\
\hline & 13 & 145 & 178 & 900 & 124 & 17,92 & 161 & 13,23 \\
\hline & 14 & 140 & 168 & 900 & 110 & 13,40 & 160 & 12,71 \\
\hline & 15 & 163 & 208 & 900 & 144 & 17,56 & 200 & 13,96 \\
\hline & 16 & 139 & 160 & 900 & 132 & 14,79 & 157 & 17,95 \\
\hline & 17 & 166 & 214 & 900 & 163 & 12,77 & 199 & 18,24 \\
\hline & 18 & 141 & 180 & 900 & 141 & 12,16 & 180 & 12,64 \\
\hline & 19 & 121 & 161 & 900 & 113 & 12,02 & 150 & 12,46 \\
\hline & 20 & 138 & 212 & 900 & 138 & 17,73 & 176 & 13,87 \\
\hline & Avg. & 149,8 & 188,7 & 900 & 137,7 & 14,28 & 176,3 & 14,47 \\
\hline \multirow{11}{*}{$\begin{array}{l}m \\
\frac{\rho}{3} \\
\frac{0}{1}\end{array}$} & 21 & 254 & 410 & 900 & 217 & 11,28 & 270 & 11,04 \\
\hline & 22 & 216 & 252 & 900 & 166 & 10,91 & 236 & 10,11 \\
\hline & 23 & 247 & 419 & 900 & 230 & 18,99 & 266 & 10,61 \\
\hline & 24 & 240 & 256 & 900 & 201 & 10,16 & 249 & 10,85 \\
\hline & 25 & 186 & 244 & 900 & 165 & 12,89 & 209 & 10,81 \\
\hline & 26 & 217 & 270 & 900 & 209 & 15,56 & 241 & 18,16 \\
\hline & 27 & 220 & 272 & 900 & 173 & 10,08 & 214 & 19,03 \\
\hline & 28 & 257 & 292 & 900 & 217 & 10,47 & 279 & 14,22 \\
\hline & 29 & 190 & 266 & 900 & 184 & 10,52 & 228 & 10,39 \\
\hline & 30 & 184 & 266 & 900 & 184 & 11,58 & 211 & 12,10 \\
\hline & Avg. & 221,1 & 294,7 & 900 & 194,6 & 12,24 & 240,3 & 12,73 \\
\hline \multirow{7}{*}{$\begin{array}{l}\text { ナ } \\
\text { 윽 } \\
\text { 윰 }\end{array}$} & 31 & 291 & 307 & 900 & 220 & 14,17 & 264 & 13,10 \\
\hline & 32 & 181 & 283 & 900 & 162 & 13,17 & 226 & 18,80 \\
\hline & 33 & 300 & 289 & 900 & 235 & 16,19 & 283 & 15,51 \\
\hline & 34 & 146 & 189 & 900 & 144 & 15,68 & 174 & 13,25 \\
\hline & 35 & 200 & 283 & 900 & 200 & 16,42 & 250 & 12,31 \\
\hline & 36 & 211 & 275 & 900 & 192 & 15,48 & 245 & 13,97 \\
\hline & 37 & 270 & 283 & 900 & 211 & 12,55 & 237 & 12,44 \\
\hline
\end{tabular}




\begin{tabular}{|c|c|c|c|c|c|c|c|c|}
\hline & 38 & 226 & 243 & 900 & 167 & 14,36 & 225 & 15,79 \\
\hline & 39 & 190 & 252 & 900 & 190 & 12,22 & 232 & 15,43 \\
\hline & 40 & 231 & 293 & 900 & 186 & 16,16 & 262 & 13,74 \\
\hline & Avg. & 224,6 & 269,7 & 900 & 190,7 & 14,64 & 239,8 & 14,43 \\
\hline \multirow{11}{*}{ 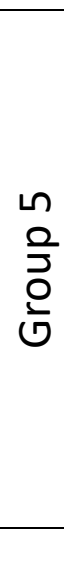 } & 41 & 257 & 236 & 900 & 75 & 22,25 & 159 & 22,01 \\
\hline & 42 & 158 & 252 & 900 & 95 & 29,76 & 161 & 19,42 \\
\hline & 43 & 259 & 344 & 900 & 109 & 22,22 & 134 & 19,85 \\
\hline & 44 & 433 & 208 & 900 & 259 & 22,08 & 204 & 30,72 \\
\hline & 45 & 206 & 267 & 900 & 105 & 33,39 & 191 & 17,53 \\
\hline & 46 & 442 & 356 & 900 & 72 & 21,42 & 187 & 17,65 \\
\hline & 47 & 366 & 317 & 900 & 112 & 24,92 & 220 & 27,45 \\
\hline & 48 & 250 & 359 & 900 & 83 & 17,57 & 147 & 21,64 \\
\hline & 49 & 599 & 250 & 900 & 326 & 17,72 & 179 & 22,75 \\
\hline & 50 & 262 & INF & 900 & 89 & 29,60 & 169 & 25,72 \\
\hline & Avg. & 323,2 & 287,67 & 900 & 132,5 & 24,09 & 175,1 & 22,47 \\
\hline \multirow{11}{*}{$\begin{array}{l}0 \\
\\
\frac{0}{7} \\
\text { 은 }\end{array}$} & 51 & 185 & 209 & 900 & 89 & 17,45 & 203 & 18,87 \\
\hline & 52 & 303 & 352 & 900 & 98 & 26,38 & 154 & 18,87 \\
\hline & 53 & 134 & 346 & 900 & 65 & 18,84 & 130 & 28,23 \\
\hline & 54 & 129 & 257 & 900 & 68 & 26,56 & 121 & 33,69 \\
\hline & 55 & 91 & 207 & 900 & 77 & 17,28 & 107 & 22,86 \\
\hline & 56 & 260 & 192 & 900 & 53 & 25,17 & 127 & 25,49 \\
\hline & 57 & 141 & 322 & 900 & 76 & 28,25 & 181 & 32,87 \\
\hline & 58 & 229 & 243 & 900 & 136 & 24,26 & 204 & 20,01 \\
\hline & 59 & 212 & 185 & 900 & 85 & 23,38 & 158 & 20,94 \\
\hline & 60 & 138 & 227 & 900 & 52 & 41,84 & 137 & 17,43 \\
\hline & Avg. & 182,2 & 254 & 900 & 79,9 & 24,94 & 152,2 & 23,93 \\
\hline \multirow{11}{*}{$\begin{array}{l}\text { No } \\
\text { 곡 } \\
\text { 인 }\end{array}$} & 61 & 513 & 282 & 900 & 167 & 24,71 & 282 & 17,86 \\
\hline & 62 & 411 & 302 & 900 & 149 & 18,46 & 258 & 20,89 \\
\hline & 63 & 239 & 307 & 900 & 210 & 24,16 & 229 & 23,38 \\
\hline & 64 & 203 & 298 & 900 & 138 & 18,34 & 163 & 19,62 \\
\hline & 65 & 650 & 444 & 900 & 116 & 22,94 & 223 & 23,85 \\
\hline & 66 & 246 & 342 & 900 & 137 & 19,65 & 186 & 17,04 \\
\hline & 67 & 236 & 245 & 900 & 98 & 21,76 & 154 & 25,17 \\
\hline & 68 & 249 & 411 & 900 & 157 & 22,31 & 199 & 22,41 \\
\hline & 69 & 316 & 347 & 900 & 147 & 19,79 & 159 & 20,96 \\
\hline & 70 & 312 & 359 & 900 & 143 & 29,36 & 188 & 19,32 \\
\hline & Avg. & 337,5 & 333,7 & 900 & 146,2 & 22,15 & 204,1 & 21,05 \\
\hline \multirow{9}{*}{ 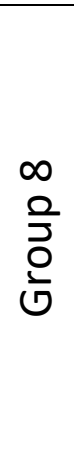 } & 71 & 284 & 259 & 900 & 127 & 24,29 & 186 & 17,22 \\
\hline & 72 & 544 & 347 & 900 & 176 & 24,34 & 303 & 22,98 \\
\hline & 73 & 426 & 382 & 900 & 216 & 22,71 & 196 & 25,91 \\
\hline & 74 & 208 & 258 & 900 & 112 & 31,72 & 169 & 36,98 \\
\hline & 75 & 515 & 325 & 900 & 104 & 19,85 & 189 & 17,10 \\
\hline & 76 & 172 & 274 & 900 & 120 & 24,08 & 164 & 38,10 \\
\hline & 77 & 327 & 321 & 900 & 150 & 34,16 & 214 & 24,91 \\
\hline & 78 & 319 & 294 & 900 & 112 & 26,12 & 144 & 24,09 \\
\hline & 79 & 666 & 291 & 900 & 164 & 17,69 & 147 & 23,95 \\
\hline
\end{tabular}




\begin{tabular}{cccccccc}
80 & 296 & 247 & 900 & 127 & 22,87 & 161 & 22,75 \\
\hline Avg. & 375,7 & 299,8 & 900 & 140,8 & 24,78 & 187,3 & 25,4 \\
\hline
\end{tabular}

Table 5. Detailed results obtained by heuristic approach for Tonge and Wee-Mag family.

\begin{tabular}{|c|c|c|c|c|c|c|c|c|c|c|}
\hline & \multirow{3}{*}{$\begin{array}{l}\text { Family } \\
\text { TONGE } \\
\text { Inst. }\end{array}$} & \multicolumn{4}{|c|}{ Heuristic Solutions } & \multirow{3}{*}{$\begin{array}{c}\text { Family } \\
\text { WEE-MAG } \\
\text { Inst. }\end{array}$} & \multicolumn{4}{|c|}{ Heuristic Solutions } \\
\hline & & \multicolumn{2}{|c|}{$\begin{array}{c}\text { Setup Level } 1 \\
(0,25)\end{array}$} & \multicolumn{2}{|c|}{$\begin{array}{c}\text { Setup Level } 4 \\
(1,00)\end{array}$} & & \multicolumn{2}{|c|}{$\begin{array}{c}\text { Setup Level } 1 \\
(0,25)\end{array}$} & \multicolumn{2}{|c|}{$\begin{array}{c}\text { Setup Level } 4 \\
(1,00)\end{array}$} \\
\hline & & 0,25 & CPU & 1 & $\mathrm{CPU}$ & & 0,25 & CPU & 1 & $\mathrm{CPU}$ \\
\hline \multirow{11}{*}{$\begin{array}{l}\text { ㄱ. } \\
\text { 윽 } \\
\text { 임 } \\
\text { iv }\end{array}$} & 1 & 127 & 829 & 153 & 721 & 1 & 49 & 785 & 86 & 777 \\
\hline & 2 & 116 & 718 & 178 & 701 & 2 & 55 & 811 & 96 & 831 \\
\hline & 3 & 125 & 723 & 163 & 805 & 3 & 44 & 759 & 77 & 812 \\
\hline & 4 & 137 & 756 & 179 & 748 & 4 & 55 & 813 & 90 & 754 \\
\hline & 5 & 118 & 739 & 168 & 776 & 5 & 53 & 750 & 80 & 829 \\
\hline & 6 & 116 & 737 & 158 & 767 & 6 & 54 & 760 & 89 & 772 \\
\hline & 7 & 133 & 753 & 153 & 849 & 7 & 52 & 848 & 83 & 901 \\
\hline & 8 & 126 & 754 & 167 & 779 & 8 & 50 & 795 & 83 & 772 \\
\hline & 9 & 100 & 704 & 150 & 730 & 9 & 52 & 752 & 83 & 795 \\
\hline & 10 & 119 & 712 & 144 & 724 & 10 & 49 & 754 & 80 & 763 \\
\hline & Avg. & 121,70 & 742,51 & 161 & 760,11 & Avg. & 51 & 782,74 & 85 & 800,68 \\
\hline \multirow{11}{*}{$\begin{array}{l}\text { ㄱ } \\
\text { 윽 } \\
\text { 은 }\end{array}$} & 11 & 137 & 737 & 197 & 711 & 11 & 54 & 780 & 85 & 773 \\
\hline & 12 & 134 & 779 & 183 & 741 & 12 & 49 & 842 & 74 & 750 \\
\hline & 13 & 132 & 721 & 176 & 812 & 13 & 51 & 796 & 78 & 769 \\
\hline & 14 & 119 & 751 & 151 & 764 & 14 & 57 & 758 & 84 & 785 \\
\hline & 15 & 113 & 726 & 153 & 764 & 15 & 61 & 750 & 92 & 820 \\
\hline & 16 & 124 & 706 & 162 & 739 & 16 & 58 & 803 & 93 & 831 \\
\hline & 17 & 150 & 940 & 165 & 717 & 17 & 54 & 787 & 87 & 863 \\
\hline & 18 & 158 & 713 & 186 & 706 & 18 & 59 & 858 & 98 & 784 \\
\hline & 19 & 144 & 711 & 185 & 833 & 19 & 56 & 767 & 87 & 788 \\
\hline & 20 & 148 & 701 & 184 & 714 & 20 & 62 & 838 & 95 & 822 \\
\hline & Avg. & 135,90 & 748,53 & 174 & 750,20 & Avg. & 56 & 797,80 & 87 & 798,60 \\
\hline \multirow{11}{*}{$\begin{array}{l}m \\
\\
\frac{0}{3} \\
\text { 은 }\end{array}$} & 21 & 196 & 703 & 219 & 786 & 21 & 78 & 921 & 117 & 825 \\
\hline & 22 & 232 & 702 & 231 & 712 & 22 & 67 & 801 & 97 & 776 \\
\hline & 23 & 169 & 754 & 217 & 762 & 23 & 77 & 845 & 112 & 798 \\
\hline & 24 & 178 & 757 & 204 & 774 & 24 & 73 & 760 & 100 & 774 \\
\hline & 25 & 216 & 749 & 271 & 710 & 25 & 70 & 767 & 93 & 754 \\
\hline & 26 & 202 & 703 & 235 & 785 & 26 & 77 & 911 & 104 & 752 \\
\hline & 27 & 174 & 714 & 215 & 715 & 27 & 75 & 795 & 100 & 776 \\
\hline & 28 & 217 & 772 & 259 & 867 & 28 & 74 & 773 & 103 & 758 \\
\hline & 29 & 207 & 765 & 250 & 702 & 29 & 72 & 753 & 99 & 756 \\
\hline & 30 & 199 & 781 & 220 & 743 & 30 & 86 & 771 & 117 & 841 \\
\hline & Avg. & 199,00 & 739,93 & 232 & 755,66 & Avg. & 75 & 809,77 & 104 & 780,91 \\
\hline \multirow{4}{*}{$\begin{array}{l}\text { ナ } \\
\frac{0}{3} \\
\text { 윤 }\end{array}$} & 31 & 197 & 758 & 229 & 741 & 31 & 77 & 800 & 100 & 817 \\
\hline & 32 & 224 & 743 & 254 & 704 & 32 & 68 & 901 & 101 & 762 \\
\hline & 33 & 222 & 710 & 246 & 712 & 33 & 76 & 797 & 107 & 770 \\
\hline & 34 & 196 & 705 & 228 & 907 & 34 & 75 & 751 & 106 & 754 \\
\hline
\end{tabular}




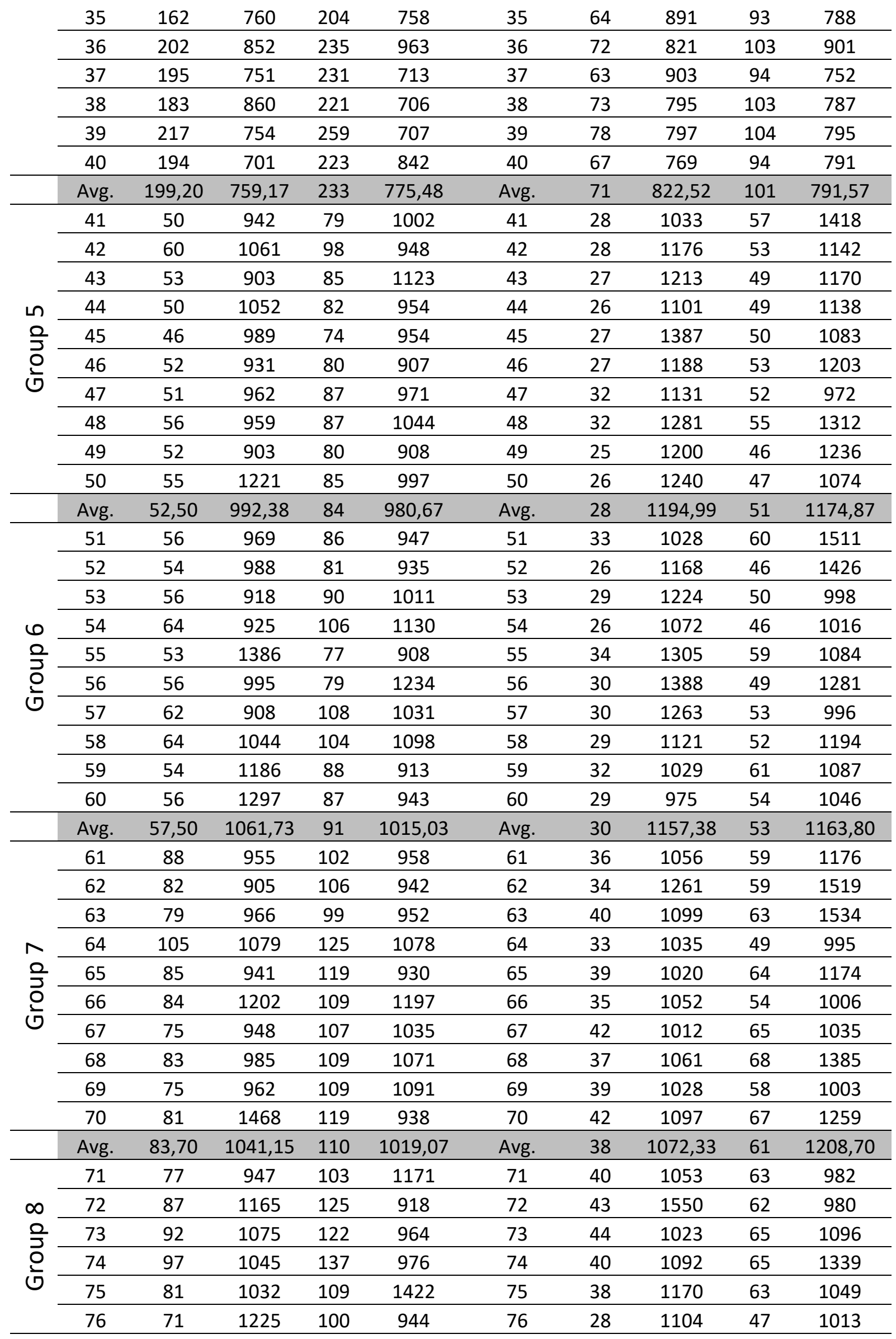




\begin{tabular}{cccccccccc}
77 & 83 & 1366 & 123 & 1114 & 77 & 37 & 1252 & 60 & 1083 \\
\hline 78 & 95 & 911 & 131 & 1013 & 78 & 39 & 1049 & 64 & 1061 \\
\hline 79 & 86 & 935 & 118 & 955 & 79 & 44 & 1099 & 69 & 971 \\
\hline 80 & 80 & 1018 & 106 & 1041 & 80 & 40 & 1012 & 63 & 995 \\
\hline Avg. & 84,90 & 1071,89 & 117 & 1051,80 & Avg. & 39 & 1140,33 & 62 & 1056,92 \\
\hline
\end{tabular}

\section{5- Results and Discussion}

In this section, the performance of algorithm on some well-known test problems taken from the ALBP literature in terms of solution quality and running time are going to be examined. Since the problem has been presented for the first time in the literature, no comparable study is reported. For this reason, the presented algorithm and mathematical model have been compared on various problems. Algorithm and mathematical model were coded in C\# language and GRUBI solver, and both were executed on a PC with Intel(R) Core(TM) i7, $2.20 \mathrm{GHz}$ processor and $8.00 \mathrm{~GB}$ of RAM under a Microsoft Windows 10 environment.

Chaves et al. applied a clustering search algorithm and generated ALWABP benchmark test instances [31]. Hereby, the presented benchmark data sets, which are composed of four families (Roszieg, Heskia, Tonge and Wee-Mag), have been used in every ALWABP research study. In addition, the test instances presented by Scholl in the literature were used in terms of sequence dependent setup times. Setup times used in this paper are 0.25 (low) and 1.00 (high) [21].

Small-size test instances used in the presented study are Roszieg and Heskia. These problems are used to compare the performance of the proposed algorithm with the mixed integer programming described in Section 2. The proposed mathematical model is solved using the GUROBI solver to find the optimal solution of the problems.

In Roszieg problem, 80 test instances with 0.25 setup time were examined, and the mathematical model optimally solved 32 of these problems. 48 of the feasible solutions found with an average Gap value of $3.91 \%$. At the same time, the proposed algorithm yielded the same results compared with the mathematical model in all test instances. In addition, the total CPU time for mathematical model solutions is 49879 seconds. This solution time is 852 seconds for the algorithm. For the same test instances, 31 problems were solved optimally with the mathematical model at 1.00 setup time, while 49 test problems produced feasible solutions with a Gap value of $31.69 \%$. Additionally, while the total time spent for mathematical model solutions is 55428 seconds, the solution time took 852 seconds in the algorithm. Furthermore, the same results were found with the mathematical model in all 160 test problems for Roszieg.

In the Heskia problem, all of the maximum times were reached for each test instances defined for the mathematical model. Thus, the mathematical model was able to yield the same result with the algorithm in only 6 of 80 test problems with 0.25 setup time. The algorithm solved the 74 problem by creating better results. The algorithm presented in all 80 test problems with 1.00 setup time, provided better solutions to all problems than the mathematical model.

Thus, the efficiency of the proposed algorithm has been shown on small-sized test problems, and the results of large-sized test problems are given for Tong and Wee-Mag families in Table- 5.

\section{6- Conclusions and future research}

In this paper, assembly line worker assignment and balancing problem with sequence-dependent setup times is introduced. For this purpose, a mathematical model formulation is developed for the 
problem. Proposed model is capable of solving some small-size instances optimally using GUROBI solver. As the mathematical model has difficulties finding optimal solutions for the real-life environment problems with a reasonable CPU time, an algorithm based on a simulated annealing is also proposed. To demonstrate the efficiency of the proposed approaches, a computational experiment is conducted. The results show that the proposed algorithm and mathematical model are effective and successful for the ALWABPS. According to our best knowledge, the presented paper is the first study for assembly line worker assignment and balancing problem with sequence-dependent setup times. This study is a good starting point for future studies. Future studies might extend the presented problem, like U-shaped assembly line balancing problems with disabled worker and setup time. The problem, which is NP-Hard problem structure, can be solved with exact solution algorithms. For this purpose, lower bound studies might be done to be used in the algorithm. Beside these, some real-life constraints, such as zoning constraints, positional constraints and so on, should be studied. Thus, the applicability of the studies in the literature to real life problems will be easier.

\section{Compliance with ethical standards}

Conflict of interest: The authors declare that there is no conflict of interest.

Human and animal rights statement: Humans/animals are not involved in this work.

\section{6-References}

[1] Serin, F., Mete, S. and Çelik, E., (2019), "An efficient algorithm for U-type assembly line rebalancing problem with stochastic task times", Assembly Automation, Vol. 39, No. 4, pp. 581595.

[2] Gökçen, H., Ağpak, K. and Benzer, R. (2006), "Balancing of parallel assembly lines", International Journal of Production Economics, Vol. 103 No. 2, pp. 600-609.

[3] Yadav, A., Kulhary, R., Nishad, R., and Agrawal, S.K. (2019), "Parallel two-sided assembly line balancing with tools and tasks sharing", Assembly Automation, DOI: https://doi.org/10.1108/AA-02-2018-025.

[4] Baykasoğlu, A. and Dereli, T. (2008), "Two-sided assembly line balancing using an ant-colonybased heuristic", International Journal of Advanced Manufacturing Technology, Vol. 36 No. 5/6, pp. 582-588.

[5] Çevikcan, E. and Durmusoğlu, MB., (2020), "A novel optimization approach for segmented rabbit chase oriented U-type assembly line design: an application from lighting industry", Assembly Automation, Vol. 40, No. 3, pp. 483-510.

[6] Ege, Y., Azizoglu, M. and Ozdemirel, N.E. (2009), "Assembly line balancing with station paralleling", Computers and Industrial Engineering , Vol. 57 No. 4, pp. 1218-1225.

[7] Yeh, D.H. and Kao, H.H. (2009), "A new bidirectional heuristic for the assembly line balancing problem", Computers and Industrial Engineering, Vol. 57 No. 4, pp. 1155-1160.

[8] Scholl, A. and Becker, C. (2006), "State-of-the-art exact and heuristic solution procedures for simple assembly line balancing", European Journal of Operational Research, Vol. 168 No. 3, pp. 666-693.

[9] Becker, C. and Scholl, A. (2006), "A survey on problems and methods in generalized assembly line balancing", European Journal of Operational Research, Vol. 168 No. 3, pp. 694-715. 
[10] Blum C. and Miralles, C. (2011), "On solving the assembly line worker assignment and balancing problem via beam search", Computers \& Operations Research, Vol. 38, pp. 328-339.

[11] Miralles, C., Garci'a-Sabater, JP., Andre's, C. and Cardos, M. (2007), “Advantages of assembly lines in sheltered work centres for disabled. A case study." International Journal of Production Economics, Vol. 110 pp. 187-197.

[12] Shin, J., Lee, M. and Morrison, JR., (2019), "On the optimization of cycle time in assembly lines with parallel workstations and tasks requiring multiple workers", IEEE 15th International Conference on Automation Science and Engineering (CASE), Vancouver, BC, Canada, pp. 916921.

[13] Dolgui A., Kovalev S., Kovalyov MY, Malyutin S. and Soukhal A. (2018) "Optimal workforce assignment to operations of a paced assembly line" European Journal of Operations Research Vol. 264, pp. 200-211.

[14] Özcan, U. and Toklu, B. (2010), "Balancing two-sided assembly lines with sequence-dependent setup times", International Journal of Production Research, Vol. 48, No. 18, pp. 5363-5383.

[15] Andres, C., Miralles, C. and Pastor, R., (2008), "Balancing and scheduling tasks in assembly lines with sequence-dependent setup times", European Journal of Operational Research, Vol. 187, No. 3, pp. 1212-1223.

[16] Scholl, A., Boysen, N. and Fliedner, M. (2008), "The sequence-dependent assembly line balancing problem", OR spectrum, Vol. 30, No. 3, pp. 579-609.

[17] Martino, L., Pastor, R. (2010), "Heuristic procedures for solving the general assembly line balancing problem with setups", International Journal of Production Research Vol. 48, No.6, pp. 1787-1804.

[18] Nazarian, E., Ko, J. and Wang, H. (2010), "Design of multi-product manufacturing lines with the consideration of product change dependent inter-task times, reduced changeover and machine flexibility", Journal of Manufacturing Systems, Vol. 29, No. 1, pp. 35-46.

[19] Seyed-Alagheband, SA., Ghomi, SF. and Zandieh, M. (2011), "A simulated annealing algorithm for balancing the assembly line type II problem with sequence-dependent setup times between tasks", International Journal of Production Research Vol. 49 No. 3, pp. 805-825.

[20] Yazdanparast, V., Hajihosseini, H. and Bahalke, A. (2011), "Cost oriented assembly line balancing problem with sequence dependent setup times", Australian Journal of Basic and Applied Sciences, Vol. 5 No. 9, pp. 878-884.

[21] Yolmeh, A. and Kianfar, F. (2012), "An efficient hybrid genetic algorithm to solve assembly line balancing problem with sequence-dependent setup times" Computers and Industrial Engineering Vol. 62 No. 4, pp. 936-945.

[22] Scholl, A., Boysen, N., Fliedner, M. (2013), "The assembly line balancing and scheduling problem with sequence-dependent setup times: problem extension, model formulation and efficient heuristics", OR spectrum Vol. 35 No. 1, pp. 291-320.

[23] Kalayci, CB. and Gupta, SM. (2013), "A particle swarm optimization algorithm with neighborhood-based mutation for sequence-dependent disassembly line balancing problem", International Journal of Advanced Manufacturing Technology, Vol. 69, No. 1-4, pp. 197-209. 
[24] Akpınar, Ş., Bayhan, GM. and Baykasoğlu, A., (2013), "Hybridizing ant colony optimization via genetic algorithm for mixed-model assembly line balancing problem with sequence dependent setup times between tasks", Applied Soft Computing, Vol. 13 No. 1, pp. 574-589.

[25] Hamta, N., Ghomi, SF., Jolai, F. and Shirazi, MA. (2013), "A hybrid PSO algorithm for a multiobjective assembly line balancing problem with flexible operation times, sequence- dependent setup times and learning effect", International Journal of Production Economics, Vol. 141 No. 1, pp. 99-111.

[26] Akpınar, Ş. and Baykasoğlu, A. (2014a), "Modeling and solving mixed-model assembly line balancing problem with setups. Part I: a mixed integer linear programming model", Journal of Manufacturing Systems, Vol. 33 No. 1, pp. 177-187.

[27] Akpınar, ş. and Baykasoğlu, A. (2014b), "Modeling and solving mixed-model assembly line balancing problem with setups. Part II: a multiple colony hybrid bees algorithm", Journal of Manufacturing Systems, Vol. 33 No. 4, pp. 445-461.

[28] Şahin, M. and Kellegöz, T. (2017), "Increasing production rate in U-type assembly lines with sequence-dependent set-up times”, Engineering Optimization, Vol. 49, No. 8, pp. 1401-1419.

[29] Akpınar, Ş., Elmi, A. and Bektaş, T. (2017), "Combinatorial Benders cuts for assembly line balancing problems with setups", European Journal of Operations Research, Vol. 259 No. 2, pp. 527-537.

[30] Özcan, U. (2019), "Balancing and scheduling tasks in parallel assembly lines with sequencedependent setup times", International Journal of Production Economics, Vol. 213, pp. 81-96.

[31] Chaves AA., Miralles C., Lorena LAN. (2007), "Clustering search approach for the assembly line worker assignment and balancing problem", Proceedings of the 37th international conference on computers and industrial engineering, Alexandria, Egypt, pp 1469-1478.

[32] Miralles C., Garcia-Sabater JP., Andres C., Cardos M. (2008), "Branch and bound procedures for solving the assembly line worker assignment and balancing problem: application to sheltered work centers for disabled", Discrete Applied Mathematics, Vol. 156, pp. 352-367.

[33] Chaves, AA., Lorena, LAN., and Miralles, C. (2009), "Hybrid metaheuristic for the assembly line worker assignment and balancing problem", Lecture Notes in Computer Science, Vol. 5818, pp. $1-14$.

[34] Moreira, MCO., Ritt, M., Costa, AM., Chaves, AA. (2012), "Simple heuristics for the assembly line worker assignment and balancing problem", Journal of Heuristics Vol. 18, pp. 505-524.

[35] Mutlu, Ö., Polat, O., Supciller, AA. (2013), "An iterative genetic algorithm for the assembly line worker assignment and balancing problem of type-II", Computers and Operations Research, Vol. 40, pp. 418-426.

[36] Vila, M. and Pereira, J. (2014), "A branch-and-bound algorithm for assembly line worker assignment and balancing problems", Computers and Operations Research, Vol. 44, pp. 105114.

[37] Ramezanian, R., Ezzatpanah, A. (2015), "Modeling and solving multi-objective mixed-model assembly line balancing and worker assignment problem", Computers and Industrial Engineering, Vol. 87, pp. 74-80. 
[38] Akyol, SD., Baykasoğlu, A. (2016), "A multiple-rule based constructive randomized search algorithm for solving assembly line worker assignment and balancing problem", Journal of Intelligent Manufacturing Vol. 30, pp. 557-573.

[39] Janardhanan, MN., Li, Z. and Nielsen, P. (2019), "Model and migrating birds optimization algorithm for two-sided assembly line worker assignment and balancing problem", Soft Computing, Vol. 23, pp. 11263-11276.

[40] Pereira, J. (2018), "The robust (minmax regret) assembly line worker assignment and balancing problem", Computers and Operations Research, Vol. 93, pp. 27-40.

[41] Li, Z., Tang, Q. and Zhang, L. (2016), "Minimizing energy consumption and cycle time in twosided robotic assembly line systems using restarted simulated annealing algorithm", Jornal of Cleaner Production, Vol. 135, pp. 508-522.

[42] Roshani, A. and Giglio, D. (2017), "Simulated annealing algorithms for the multi-manned assembly line balancing problem: minimising cycle time", International Jornal of Production Research, Vol. 55, No. 10, pp. 2731-2751.

[43] Kirkpatrick, S., Gelatt, CD., and Veechi, MP. (1983), "Optimization by simulated annealing", Science Vol. 220, pp. 671-679.

[44] Ritt, M., Costa, AM., and Miralles, C. (2015), "The assembly line worker assignment and balancing problem with stochastic worker availability", International Journal of Production Research, Vol. 54, No. 3, pp. 907-922.

[45] Yang, W. and Cheng, W. (2020), "A Mathematical Model and a Simulated Annealing Algorithm for Balancing Multi-manned Assembly Line Problem with Sequence-Dependent Setup Time", Mathematical Problems in Engineering, Vol. 2020, pp. 1-16. 
Figures

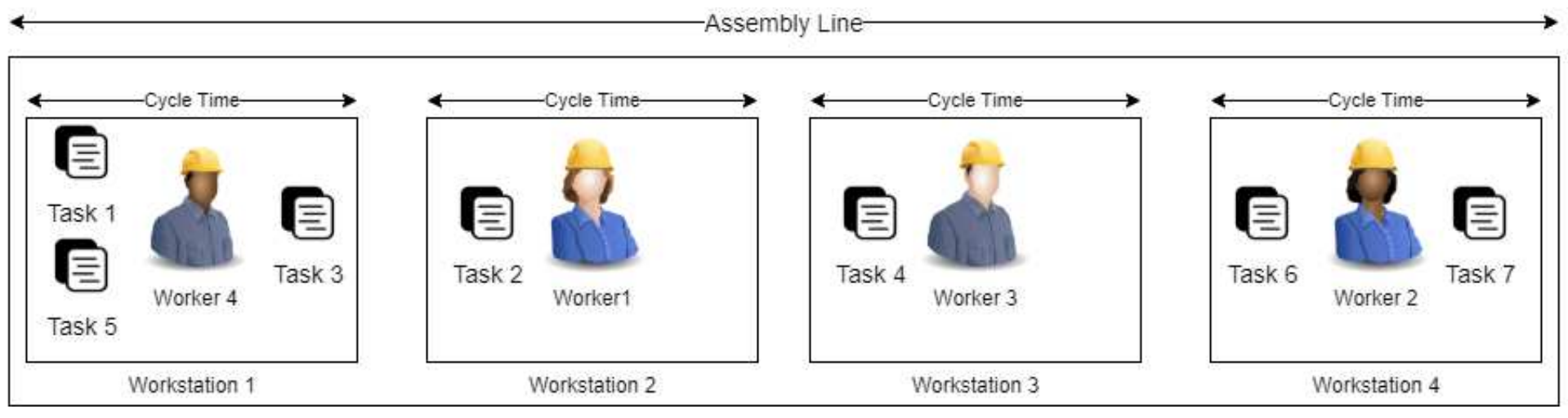

Figure 1

Assignment example of workers and tasks for ALWABP

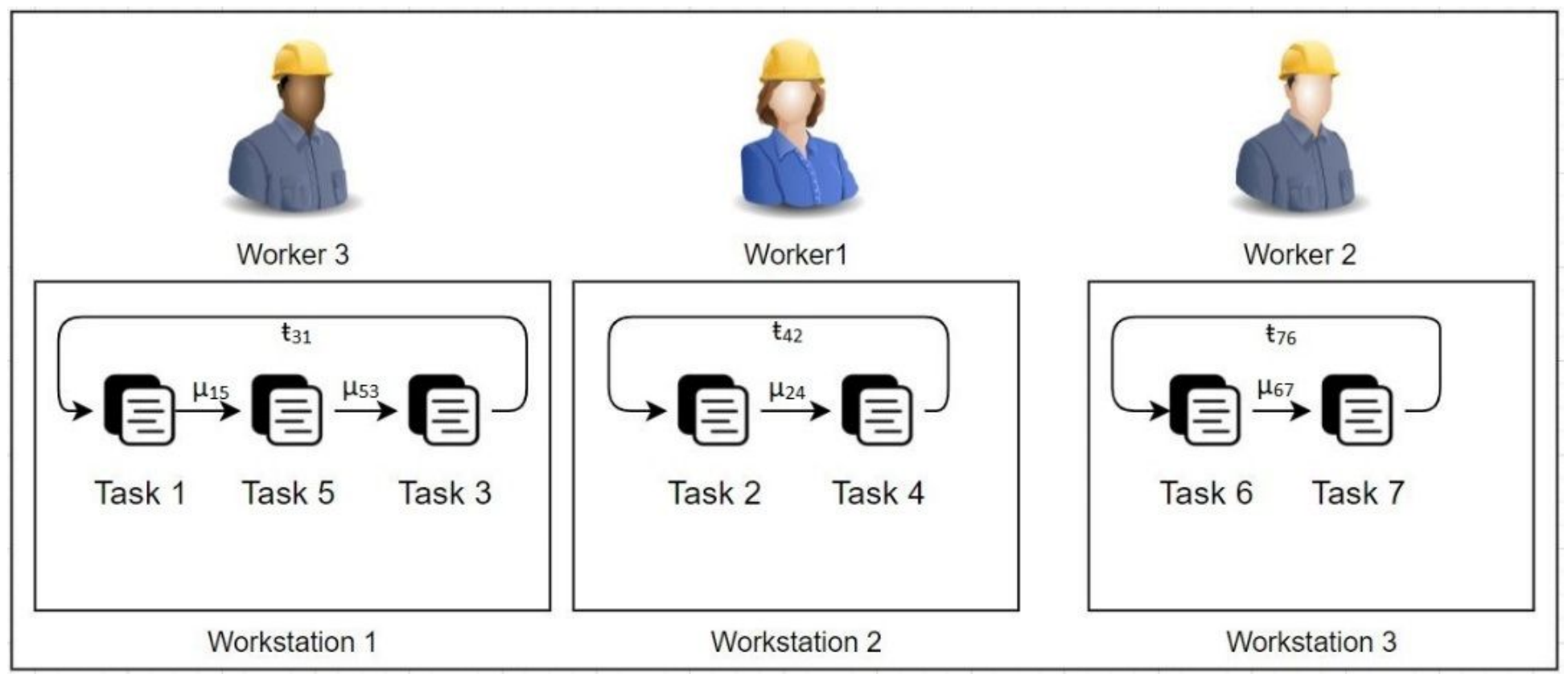

Figure 2

Illustration of ALWABP with sequence-dependent setup times. 

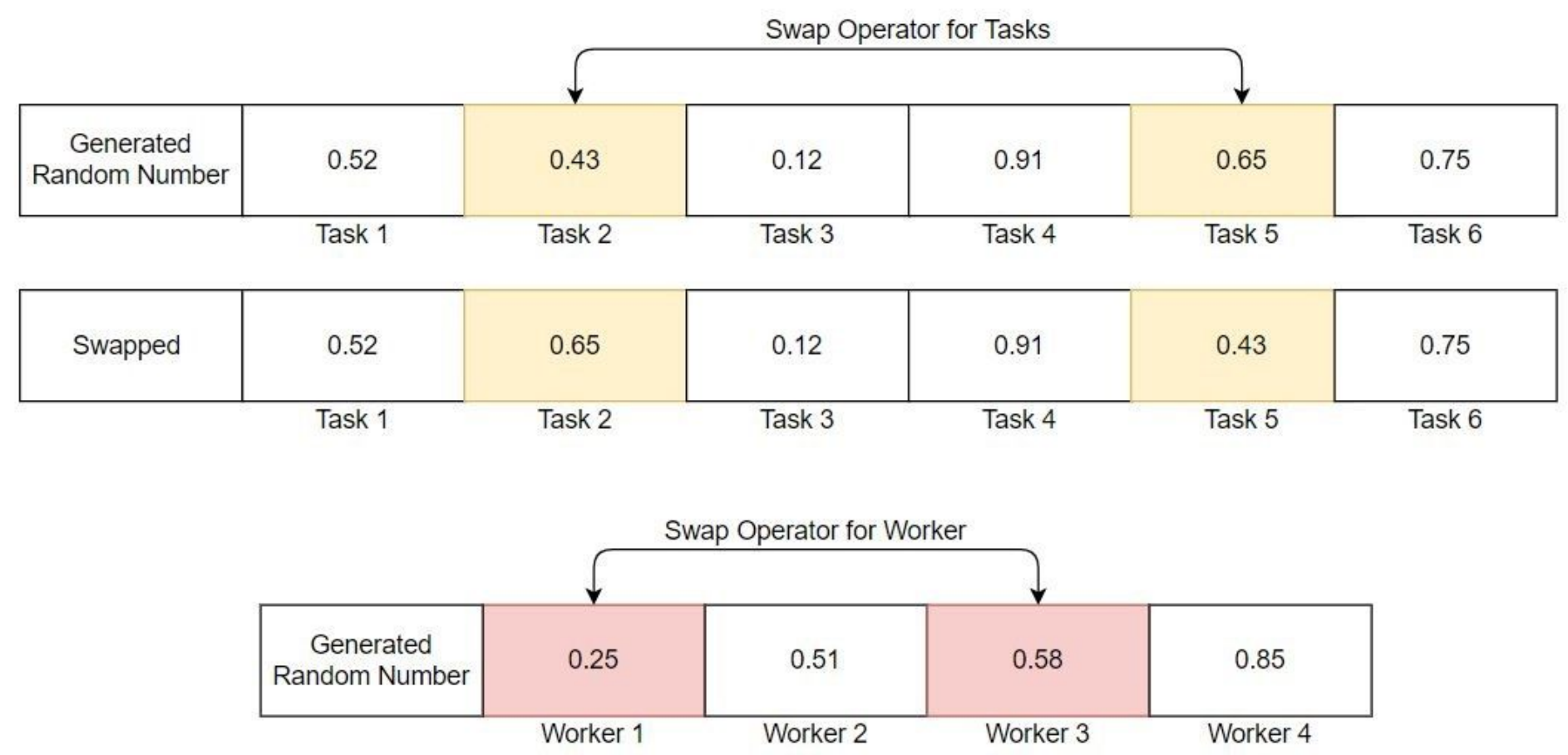

\begin{tabular}{|c|c|c|c|c|}
\hline Swapped & 0.58 & 0.51 & 0.25 & 0.85 \\
\hline
\end{tabular}

\section{Figure 3}

Swap operator for the worker and tasks. 